\title{
Teor de óleo essencial de alecrim-pimenta em função do horário de colheita
}

\author{
Essential oil content of pepper-rosmarin as a function of harvest time
}

\section{Marco Túlio Pinheiro de Melo ${ }^{I}$ Juliana Martins Ribeiro ${ }^{\mathrm{II}}$ Messulan Rodrigues Meira ${ }^{\mathrm{III}}$ Lourdes Silva de Figueiredo ${ }^{\mathrm{IV}}$ Ernane Ronie Martins $^{\mathrm{IV}}$}

\section{RESUMO}

O alecrim-pimenta é uma importante planta medicinal, nativa do nordeste brasileiro, que, devido ao seu óleo essencial, apresenta grande potencial antifúngico e antibacteriano. Um dos fatores que afetam o teor de metabólitos secundários das plantas é o horário de colheita, assim, o conhecimento desse fator subsidia as decisões agronômicas da espécie, favorecendo o aumento do teor de óleo essencial no momento da colheita. Dessa forma, o objetivo do presente trabalho foi avaliar o efeito do horário de colheita na produção de óleo essencial de alecrim-pimenta (Lippia sidoides Cham.). O experimento foi desenvolvido no Instituto de Ciências Agrárias da Universidade Federal de Minas Gerais (ICA/UFMG), Montes Claros, Minas Gerais, Brasil. Utilizou-se o delineamento experimental em blocos casualizados com cinco tratamentos, definidos pelos horários de coleta das folhas (6:00, 9:00, 12:00, 15:00 e 18:00) e seis repetições, sendo esse o número de coletas em cada tratamento. As folhas foram obtidas de plantas matrizes do Horto Medicinal do ICA/UFMG. O óleo essencial foi obtido pelo método de hidrodestilação usando o aparelho de Clevenger. A análise de regressão apresentou um efeito cúbico para o teor de óleo essencial, sendo que o maior valor, $5,78 \%$ em relação à matéria seca, foi obtido às 9 h59min. Portanto, recomenda-se a colheita das folhas de alecrimpimenta próximo das $10 \mathrm{~h}$.

Palavras-chave: Lippia sidoides Cham., plantas medicinais, timol, carvacrol, monoterpenos.

\section{ABSTRACT}

The pepper-rosmarin is an important medicinal plant, native of Northeast of Brazil, that, because of its essential oil, presents great antifungal and antibacterial potential. One of the factors that affect the secondary metabolites content of plants is the harvest time, thus, the knowledge of this factor subsidizes the decisions agronomic species, favoring the increase of essential oil content at the harvest moment. Thus, the aim of this research was to evaluate the effect of harvest time on the essential oil production of pepper-rosmarin (Lippia sidoides Cham.). The experiment was carried out in the Instituto of Ciências Agrárias of Universidade Federal of Minas Gerais (ICA/UFMG), Montes Claros, Minas Gerais, Brazil. It was installed in a randomized block design, with five treatments consisted by harvest times (6:00, 9:00, 12:00, 15:00 and 18:00) with six replications (number of collections in each treatment). The leaves were obtained from stock plants of medicinal vegetable garden of ICA/ UFMG. The essential oil was obtained by hydrodistillation in a Clevenger apparatus. The regression analysis presented a cubic effect to the essential oil content, being that the highest value, 5,78\% in relation to dry matter, was obtained at 9h59min. Therefore, it was recommended the harvest time of pepper-rosmarin leaves next to $10 \mathrm{~h}$.

Key words: Lippia sidoides Cham., medicinal plants, thymol, carvacrol, monoterpenes.

\section{INTRODUÇÃO}

O alecrim-pimenta (Lippia sidoides Cham.) é uma planta medicinal da família Verbenaceae, própria da vegetação do semi-árido, com origem no nordeste do Brasil. A espécie apresenta porte arbustivo, ereto,

'Programa de Pós-graduação Ciências Agrárias, Instituto de Ciências Agrárias (ICA), Universidade Federal de Minas Gerais (UFMG), 39400-000, Montes Claros, MG, Brasil. E-mail: mtuliomelo@hotmail.com. Autor para correspondência.

"Curso de Engenharia Agronômica, ICA, UFMG, Montes Claros, MG, Brasil.

IIIPrograma de Pós-graduação em Ciências Agrárias, ICA, UFMG, Montes Claros, MG, Brasil.

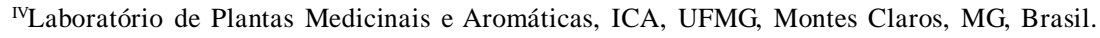


com muitas ramificações, podendo atingir até três metros de altura. Possui folhas muito aromáticas e picantes que apresentam óleo essencial rico em timol e carvacrol (LORENZI \& MATOS, 2008), monoterpenos responsáveis pela atividade antimicrobiana apresentada pela espécie (LEMOS et al., 1990). Destacase pela sua utilização na preparação de medicamentos anti-sépticos de uso tópico, possuindo relevantes aplicações em farmácia, medicina, odontologia e saúde pública (MATOS \& OLIVEIRA, 1998).

Os fatores ambientais podem causar alterações nas plantas, pois o aroma de cada espécie varia ao longo do dia, demonstrando que o horário de colheita do material pode ser um fator importante para a produção de óleos essenciais (NASCIMENTO et al., 2006). Segundo MARTINS \& SANTOS (1995), existem horários em que a concentração dos princípios ativos na planta é maior, mas isso varia de espécie para espécie. De acordo com SILVAet al. (2003), os menores teores de óleo essencial podem estar relacionados à presença de orvalho sobre as folhas, que aumentam a umidade e diminuem a quantidade de material a ser extraído, e às altas temperaturas, que podem causar volatilização do óleo essencial. Assim, o conhecimento da influência desses fatores é importante nas decisões agronômicas de cultivo e colheita das plantas medicinais (FONSECA et al., 2007).

Objetivando-se contribuir para a otimização do rendimento de óleo essencial do alecrim-pimenta, o presente trabalho visou a avaliar o efeito do horário de colheita das folhas nos teores de óleo essencial.

\section{MATERIAL E MÉTODOS}

O trabalho foi desenvolvido no Instituto de Ciências Agrárias da Universidade Federal de Minas Gerais (ICA/UFMG), no mês de abril de 2009.

As amostras foram obtidas de plantas matrizes do Horto Medicinal do ICA/UFMG. O delineamento experimental utilizado foi o em blocos casualizados, com cinco tratamentos, que foram definidos pelos horários de colheita (6:00, 9:00, 12:00, 15:00 e 18:00h), e seis repetições, sendo esse o número de coletas em cada tratamento.

Em cada horário, foram coletados $50 \mathrm{~g}$ de folhas para avaliação do rendimento de óleo essencial e, em seguida, elas foram submetidas à extração pelo método de hidrodestilação usando o aparelho de Clevenger, expressando o seu teor com base na matéria seca da amostra. Para determinação da matéria seca, as amostras, após extração do óleo, foram mantidas em estufa de circulação forçada de ar a $65^{\circ} \mathrm{C}$, até peso constante.
Os resultados foram submetidos à análise de regressão. Utilizou-se o programa SAEG - Sistema para Análises Estatísticas e Genéticas (RIBEIRO JÚNIOR, 2001). Antes da realização da análise de variância, fez-se uma análise exploratória, utilizando o teste de Cochran e Bartlett, dos dados para identificação da homogeneidade entre as variâncias dos resultados. Como os resultados mostraram que há homogeneidade para o nível de 5\% de significância, a análise de regressão foi realizada com os dados originais (BANZATO \& KRONKA, 2006).

\section{RESULTADOS E DISCUSSÃO}

Os teores de óleo essencial e de umidade podem ser visualizados na tabela 1 . O teor de umidade das plantas oscilou durante o experimento, sendo que o seu valor médio foi de $71,37 \%$.

A análise de regressão mostrou um comportamento cúbico para o teor de óleo essencial, indicando valores diferentes entre os horários de colheita das folhas de alecrim-pimenta (Lippia sidoides Cham.) (Figura 1), sendo que o maior valor foi de 5,78\%, com coleta às $9 \mathrm{~h} 59 \mathrm{~min}$.

Resultados semelhantes podem ser encontrados nos trabalhos com as espécies Cymbopogon winterianus Jowitt (BLANK et al., 2007), Ocimum basilicum L. (CARVALHO FILHO et al., 2006), Mentha piperita L. Huds (SOUZA et al., 2006), e Porophyllum ruderale Jacq. Cassini (FONSECA et al., 2007), que recomendam colheitas, para extração do óleo essencial das folhas, no período da manhã. Esses resultados podem estar relacionados ao fator de que as plantas acumulam óleo essencial durante a noite e, no decorrer do dia, o perdem por volatilização.

Porém, os resultados do presente trabalho contrastam com os encontrados por BLANK et al. (2005) ao trabalharem com Melissa officinalis L., já que recomendam o horário de $17 \mathrm{~h}$ para colheita das folhas. Essa diferença na produção de óleo varia de acordo com a espécie, uma vez que a M. officinalis é uma planta de

Tabela 1 - Teores de óleo essencial e de umidade das plantas em cada horário de colheita.

\begin{tabular}{lcc}
\hline Tratamentos & $\begin{array}{c}\text { Teor de óleo } \\
\text { essencial }(\%)\end{array}$ & $\begin{array}{c}\text { Teor de umidade } \\
(\%)\end{array}$ \\
\hline $6: 00$ & $3,08 \pm 0,59$ & $73,53 \pm 1,17$ \\
$9: 00$ & $5,64 \pm 0,58$ & $72,75 \pm 1,18$ \\
$12: 00$ & $5,38 \pm 0,51$ & $72,66 \pm 0,84$ \\
$15: 00$ & $4,36 \pm 0,73$ & $68,14 \pm 2,91$ \\
$18: 00$ & $4,78 \pm 0,18$ & $69,76 \pm 1,82$ \\
\hline
\end{tabular}




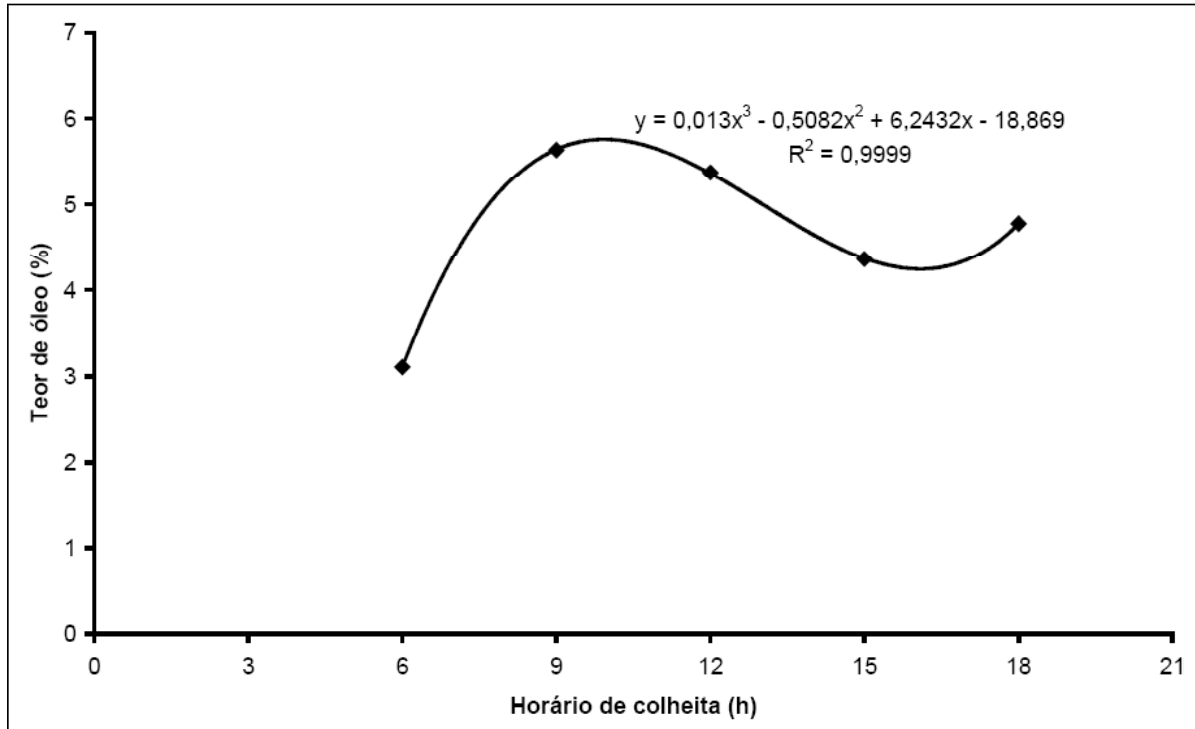

Figura 1 - Teor de óleo essencial de alecrim-pimenta, porcentagem em relação à matéria seca, em função do horário de colheita.

clima frio, enquanto a $\boldsymbol{L}$. sidoides é natural de regiões com temperaturas elevadas. Os resultados do presente trabalho também divergem dos encontrados por NAGAO et al. (2004) e SANTOS et al. (2004) ao trabalharem com Lippia alba, pois recomendam o horário de $15 \mathrm{~h}$ para colheita da espécie. SANTOS et al. (2004) atribuem esse resultado às variações na temperatura e na intensidade luminosa ao longo do dia.

Segundo SILVA et al. (2003), os teores de óleo essencial são influenciados pelas diferentes umidades e temperaturas ao longo do dia. Dessa forma, o conhecimento do horário ideal para colheita das plantas, visando à obtenção de maiores teores de princípios ativos, é de fundamental importância nas decisões agronômicas de produção.

O menor valor encontrado foi $3,08 \%$, correspondente ao horário de colheita de $6 \mathrm{~h}$ da manhã, que, segundo SILVA et al. (2003), pode estar relacionado à presença de orvalho nas folhas, o qual aumentaria a umidade fazendo com que haja uma diminuição da quantidade de material a ser extraído. Essa afirmaçãoé ilustrada na tabela 1 , na qual o valor do teor de umidade das plantas, para o horário de $6 \mathrm{~h}$, é superior aos demais horários.

\section{CONCLUSÃO}

O horário de colheita afeta o teor de óleo essencial de $\boldsymbol{L}$. sidoides (alecrim-pimenta), sendo recomendado o horário em torno de 10:00 da manhã, visando à obtenção do maior teor de óleo essencial.

\section{AGRADECIMENTOS}

À Fundação de Amparo à Pesquisa do Estado de Minas Gerais (FAPEMIG), ao Conselho Nacional de Desenvolvimento Científico e Tecnológico (CNPq) e ao Programa de Educação Tutorial (PET/Sesu-MEC) pelo apoio.

\section{REFERÊNCIAS}

BANZATTO, D.A.; KRONKA, S.N. Experimentação agrícola. Jaboticabal: FUNEP, 2006. 237p.

BLANK, A.F., et al. Influência do horário de colheita e secagem de folhas no óleo essencial de melissa (Melissa officinalis L.) cultivada em dois ambientes. Revista Brasileira de Plantas Medicinais,. v.8, p. 73-78, 2005. Disponível em: <http:// www.ibb.unesp.br/servicos/publicacoes/rbpm/pdf_v8_n1_2005/ artigo14_v8_n1.pdf >. Acesso em: 07 mar. 2011.

BLANK, A.F., et al. Influence of season, harvest time and drying on Java citronella (Cymbopogon winterianus Jowitt) volatile oil. Brazilian Journal of Pharmacognosy. v.17, p. 557-564, 2007. Disponível em: <http://www.scielo.br/scielo.php?pid=S0102$695 X 2007000400014 \&$ script $=$ sci_arttext\&tlng=en $>$. Acesso em: 07 mar. 2011. doi: 10.1590/S0102-695X2007000400014.

CARVALHO FILHO, J.L.S., et al. Influence of the harvesting time, temperature and drying period on basil (Ocimum basilicum L.) essential oil. Brazilian Journal of Pharmacognosy, v.16, p. 24, 2006. Disponível em: <http://www.scielo.br/ scielo.ph p s c ri pt $=$ sci_art text \& pid=S $0102-$ 695X2006000100007>. Acesso em: 07 mar. 2011. doi: 10.1590/ S0102-695X2006000100007.

FONSECA, M.C.M., et al. Influência da época e do horário de colheita nos teores de óleo essencial e de taninos em couvecravinho (Porophyllum ruderale) (Jacq.) Cassini. Revista Brasileira de Plantas Medicinais, v.9, p. 75-79, 2007. 
Disponível em: <http://www.ibb.unesp.br/servicos/publicacoes/ rbpm/pdf_v9_n2_2007/artigo9_v9n2_75-79.pdf>. Acesso em: 07 mar. 2011.

LEMOS, T.L.G., et al. Antimicrobial activity of essential oil of Brazilian plants. Phytotherapy Research, v.4, p.82-84, 1990.

LORENZI, H.; MATOS, F.J.A. Plantas medicinais no Brasil: nativas e exóticas. Nova Odessa: Instituto Plantarum, 2008. 544p.

MARTINS, E.R; SANTOS, R.H.S. Plantas medicinais: uma alternativa terapêutica de baixo custo. Viçosa: UFV, Imprensa universitária. 1995. 26p.

MATOS, F.J.A; OLIVEIRA, F. Lippia sidoides Cham. Farmacognosia, química e farmacologia. Revista Brasileira de Farmacognosia, v.79, p. 84-87, 1998.

NAGAO, E.O., et al. Efeito do horário de colheita sobre o teor e constituintes majoritários de óleo essencial de Lippia alba (Mill) N.E.Br., quimiotipo citral-limoneno. Ciência Agronômica, v.35, p. 355-360, 2004.
NASCIMENTO, I.B., et al. Influência do horário de coleta na produção de óleo essencial de capim santo (Andropogum sp.). Revista Caatinga, v.19, p. 123-127, 2006.

RIBEIRO JÚNIOR, J.I. Análises estatísticas no SAEG. Viçosa: UFV. 2001. 301p.

SILVA, S.R.S., et al. Análise dos constituintes químicos e da atividade antimicrobiana do óleo essencial de Melaleuca alternifolia Cheel. Revista Brasileira de Plantas Medicinais, v.6, p. 63-70, 2003.

SANTOS, M.R.A., et al. Caracterização anatômica das estruturas secretoras e produção de óleo essencial de Lippia Alba (Mill.) N.E.Br. em função do horário de colheita nas estações seca e chuvosa. Revista Ciência Agronômica, v. 35, p. 377-383, 2004.

SOUZA, W.P., et al. Avaliação do teor e da composição química do óleo essencial de Mentha piperita (L.) Huds durante o período diurno em cultivo hidropônico. Revista Brasileira de Plantas Medicinais, v.8, p.108-111, 2006. Disponível em: <http:// www.ibb.unesp.br/servicos/publicacoes/rbpm/pdf_v8_n4_2006/ artigo21_v8_n4_p108-111.pdf >. Acesso em: 07 mar. 2011. 